\title{
lon Leaching from Implantable Medical Devices
}

\author{
L.E. Eiselstein ${ }^{1, a}$, R.D. Caligiuri ${ }^{1, b}$ \\ ${ }^{1}$ Exponent, 149 Commonwealth Dr., Menlo Park, CA 94025 USA \\ a eisel@exponent.com; ${ }^{b}$ caligiuri@exponent.com
}

Keywords: Implantable medical device, corrosion, leaching, biocompatibility, invivo, in-vitro environments

\begin{abstract}
Implantable medical devices must be able to withstand the corrosive environment of the human body for 10 or more years without adverse consequences. Most reported research and development has been on developing materials and devices that are biocompatible and resistant to corrosion-fatigue, pitting, and crevice corrosion. However, little has been directly reported regarding implantable materials with respect to the rate at which they generate soluble ions in-vivo. Most of the biocompatibility studies have been done by examining animal implants and cell cultures rather than examining the rate at which these materials leach ions into the body. This paper will discuss what is currently known about the rate at which common implant materials (such as stainless steels, cobalt-chromium alloys, and nitinol) elute ions under in vitro conditions, what the limitations are of such data, and how this data can be used in medical device development.
\end{abstract}

\section{Introduction}

Implantable medical devices are expected to operate trouble-free in a corrosive aqueous environment for, in some cases, over 30 years or more. Although the in-vivo environment is well controlled by homeostasis, keeping the $\mathrm{pH}$, chemistry and temperature relatively constant compared with many consumer products, it is however, a corrosive environment. The corrosivity of the in-vivo environment is primarily affected by the dissolved oxygen and salt content of the body, i.e., an oxygenated $0.9 \mathrm{wt} \% \mathrm{NaCl}$ solution.

Ratner has succinctly summarized many of the issues regarding the testing of materials for biocompatibility [1]. He notes that animal experiments are expensive and of somewhat questionable value for predicting human response, that human clinical trials are very expensive, and that there is currently no physical or chemical measurements that can reliably predict the in-vivo biocompatibility of biomaterials. Currently, with respect to metallic implants, one of the test standards is to evaluate the material's resistance to localized corrosion through the use of electrochemical polarization testing [2]-[4]. Obviously, if a passive metal implant pits in-vivo, there is likely to be an adverse biological response to the high rate of metal ion release. This type of testing, however, does not look at the rate at which metal ions leach from the implant's surface while undergoing uniform corrosion. Even though these uniform corrosion rates will provide a much lower metal ion release rate, there could still be adverse tissue reaction [5]. Currently there is no generally accepted practice to determine the rate of metal or other ions from biomaterials. In the article we well briefly review some of this data.

In-Vitro Corrosion Metals. Stainless steels, cobalt-chromium, and nitinol alloys are commonly used in implantable medical devices. Herting et al., has investigated the effect of various simulate physiological solutions (Gamble's solution and ALF artificial lysosomal fluid) on the rate of metal ion leaching from various stainless steels [6]. They found metal dissolution decreases with exposure time and for stainless steels the metal 
ion leaching rate is faster at $\mathrm{pH} 4.5$ than at 7.4. For instance, Herting et al., observed the average metal ion release rate on the first day of exposure of $316 \mathrm{~L}$ stainless steel in the "as-received" surface condition to ALF solution ( $\mathrm{pH} 4.5)$ to be $5.3(\mathrm{Fe}), 0.40(\mathrm{Cr})$, and $0.33(\mathrm{Ni}) \mu \mathrm{g} \mathrm{cm}^{-2}$ per week, respectively. The release rate averaged over the first week had dropped to $1.2(\mathrm{Fe}), 0.1(\mathrm{Cr})$, and $0.08(\mathrm{Ni}) \mu \mathrm{g} \mathrm{cm}^{-2}$ per week, respectively. The average metal ion release rates in $\mathrm{pH} 7.4$ Gamble's solution was at least one order of magnitude lower, with the one week average values being $0.075(\mathrm{Fe}), 0.002(\mathrm{Cr})$, and $0.006(\mathrm{Ni}) \mu \mathrm{g} \mathrm{cm}^{-2}$ per week, respectively. Pre-exposure to Gamble's solution for 8 to 24 hours reduces the total metal ion leaching rate during one week's exposures to the higher $\mathrm{pH}$ ALF solutions. This suggests that calcium and phosphate deposit during the preexposure to Gamble's solution at $\mathrm{pH} 7.5$ and act to limit further metal ion leaching [6], [7].

Ornberg et al., has reported the metal ion release rate of passivated $\mathrm{Ni}-\mathrm{Co}-\mathrm{Cr}$ alloy $35 \mathrm{~N} \mathrm{LT}$ (36Ni33Co20Cr10Mo), exposed to phosphate buffered saline ( $\mathrm{pH} 7.4$ ) to which $100 \mathrm{mM} \mathrm{H}_{2} \mathrm{O}_{2}$ was added to simulate immunological response, to be $0.55(\mathrm{Ni}), 0.175(\mathrm{Cr})$, and $0.125(\mathrm{Co}) \mu \mathrm{g} \mathrm{cm}^{-2}$ per week, respectively [8] after 3 hours of exposure. These leaching values are probably higher than what is observed for the stainless steel due to the short exposure time and the oxidizing effect of the peroxide. From this research we observe that the dissolution rate of metal ion from medical implants is a function of both in-vitro chemistry and exposure time. Very little, if any, data exists for in-vivo metal leaching rates.

\section{Difference between In-Vivo and In-Vitro Leaching of Silica from an Active} Implantable Electronic Device (AIMD). Active implantable medical devices have a promising future but key safety issues must be resolved [9]. An implantable medical device (AIMD) is any medical device that relies on any source of power (e.g., electrical) other than that generated by the human body or gravity to perform its function. Examples of AIMDs include: pacemakers, implantable defibrillators, auditory brainstem implants, neuro-stimulators for nerves, diaphragm, and bladder, cochlear devices, implantable active drug administration, artificial retinal implants, deep brain stimulation (DBS), etc. Operating electronics in salt laden environments, such as the human body has always been challenging. Currently there are many methods used to protect such active electronic devices such as hermetically sealing them in packages or coating them with various materials to prevent exposure to the environment. However, a number of these devices cannot be easily protected by hermetically sealing them in a package, such as retinal implants. In other cases, the designer desires the product to be resistant to the environment in the event that the coating or sealing system leaks or otherwise fails to enhance in-vivo device reliability.

For instance, new advanced designs require the use of conformal coatings such as parylene or polyimide and inorganic films such as silica or silicon nitride to replace the hermetically sealed metal cans previously used, which separate the electronics from the in-vivo environment [10]. These thin coatings must not leach toxic elements or compounds into the body and prevent the saline environment from affecting the electrical performance over decades of service life. As an example of where there are unanticipated differences between in-vivo and in-vitro testing, test data indicates silica coatings (frequently used as passivation materials on consumer electronics) are more rapidly dissolved in-vivo than in-vitro in $0.9 \mathrm{wt} \%$ saline compared with material that had been implanted in an animal [11]-[13].

In-Vivo Compared to In-Vitro Dissolution of Silica. Hämmerle et al., has demonstrated that silica deposited by low pressure chemical vapor deposition (LP-CVD) of tetra-ethyl- 
ortho-silicate $(\mathrm{TEOS})^{1}$ has an in-vivo dissolution rate of 600 to $1000 \mathrm{~nm}$ per year; whereas no significant damage $(<90 \mathrm{~nm} / \mathrm{yr})^{2}$ was found on in-vitro ${ }^{3}$ exposed chips that had been immersed in saline for up to 21 months. The silica layer had dissolved in-vivo ${ }^{4}$ within 6 to 12 months, damaging the underlying silicon layer [11]. Rojahn et al., also comments on the work of Hämmerle et al., and cites Fromherz as further evidence of rapid dissolution of silica when exposed to brain tissue [13].

Maloney et al., have measured in-vivo ${ }^{5}$ dissolution rates of silica as $3.5 \mathrm{~nm}$ per day $\left(1,277 \mathrm{~nm}\right.$ per year) for plasma enhanced chemical vapor deposition (PECVD) ${ }^{6}$ silicon oxide [12]. Maloney et al., have plotted the film thinning over time and the rate of silica dissolution appears to be linear with time.

Brady and Walther show that the dissolution rate of pure silica is relatively constant at a rate of $0.86 \mathrm{~nm}$ per year when exposed to solutions with $\mathrm{pH}$ 's that range from 2.0 to $\mathrm{pH}$ 7.5 [14]-[15]. This $\mathrm{pH}$ range is significantly broader than the range expected in-vivo (accounting for the immunological response). Icenhower and Dove also report amorphous silica dissolution rates of 0.86 to $2.7 \mathrm{~nm}$ per year in distilled water at $25^{\circ} \mathrm{C}$ and $40^{\circ} \mathrm{C}$, respectively. They report that the addition of $0.05 \mathrm{~m} \mathrm{NaCl}$ at $40^{\circ} \mathrm{C}$ increased the rate by about a factor of $10 \mathrm{x}$ to $27 \mathrm{~nm}$ per year [16]. These rates are significantly slower (by a factor of 1000) than what has been observed in-vivo, keeping in mind that the in-vivo rates are measured on silica, incorporating some hydrogen since it is grown from TEOS and may dissolve faster than quartz or amorphous silica.

In addition there have been many studies on the dissolution rate of silica containing mineral fibers stimulated by human health concerns since such mineral fibers can be detrimental to health if they do not dissolve sufficiently rapid in-vivo [17]-[22]. The majority of this data is not directly comparable to TEOS silica dissolution since these fibers are not pure silica but generally contain an appreciable of alkaline earth oxides and other oxides. For instance, the dissolution rate of pure silica $(0.86 \mathrm{~nm}$ per year) in water is significantly lower than the dissolution rate of high silica (62 $\mathrm{wt} \%$ silica) containing mineral fibers (330 or 3,400 nm per year at $\mathrm{pH} 4.5$ or 7.7 , respectively, in Gamble's solution $^{7}$ ). How much this effect is due to the alkaline/alkali oxidation and how much to the organic components of the Gamble's solution is unknown [18].

In summary there appears to be biological processes going on in-vivo that has not been duplicated in-vitro.

Factors Affecting Dissolution of Silica. The dissolution rate of silica as a function of $\mathrm{pH}$, salinity, and other conditions are discussed in a number of references [14]-[16], [23]-

1 The first layer was a $15 \mathrm{~nm}$ deposit of high-quality low pinhole density thermally grown oxide ( $30 \mathrm{~min}$. at $900^{\circ} \mathrm{C}$ in oxygen. The thermally grown oxide grows to slow to achieve the desired $500 \mathrm{~nm}$ thickness and therefore LP-CVD at $395^{\circ} \mathrm{C}$ for 60 seconds using TEOS to grow the outer layer [Hämmerle, 2002].

2 Hämmerle does not give an estimate of their minimum detectable dissolution rate. We estimate this rate to be approximately less than $90 \mathrm{~nm}$ per year ( $0.24 \mathrm{~nm}$ per day) based on interference color change over 21 months.

3 For in-vitro testing Hämmerle's chips were exposed to phosphate buffered saline containing $0.2 \%$ sodium azide to prevent the growth of bacterial (PBS) in order to assess the biostability of the implants.

4 In-vivo exposure was performed by implanting the chips in the subretinal space in either rabbit or minipig eyes. The retina was reattached with the conventional surgical means, e.g., infusion of $\mathrm{SF}_{6}$ gas [Hämmerle, 2002].

5 In-vivo testing was done by implanting the chips in the back of rats for up to 300 days.

6 Deposition temperature was $350^{\circ} \mathrm{C}$ and $1,060 \mathrm{~nm}$ thickness of silica was deposited. The precursors for the silicon oxide film were $\mathrm{SiH}_{4}, \mathrm{~N}_{2} \mathrm{O}, \mathrm{He}$, and $\mathrm{N}_{2}$, and the deposition rate [Maloney, 2005].

7 Citrate is used in Gamble's solution to replace proteins and acetate to represent organic acids [Herting, 2007]. 
[28]. All these studies seem to give much lower rates of dissolution compared to these invivo results. Generally, the corrosion or dissolution mechanism for silica is the formation of a hydrated surface that dissolves to form aqueous $\mathrm{Si}(\mathrm{OH})_{4}$, although the specific mechanism is thought to include several coupled mechanisms: hydration, hydrolysis of covalent network, and exchange between alkali ions and protons in solution involving protonation-deprotonation reactions [12], [14], [23], [24], [29]. For instance, the buildup of silica in the test solution can ultimately saturate the solution with silica, and slow dissolution process by up to a factor of 1000. Correspondingly, the effect of surface area to solution volume ratio on dissolution rate has been known for over 30 years [17]. Recently, however, Cilleteau et al., have reported that in some cases this sharp drop in glass corrosion may not be associated with the solution saturation effect but instead a result of densification of the outer layers of the surface film [29]. In addition, there is recent research that indicates the presence of certain cations and organic compounds will also affect the dissolution rates [24], [25]. For instance, Bennett has reported the multifunctional organic acids such as citrate and oxalate accelerate quartz dissolution by decreasing the activation energy by approximately $20 \%$ while increasing silica by $100 \%$ [25].

In-Vivo Dissolution Silica. The biochemical process responsible for the rapid rate of dissolution of silica in-vivo but not in-vitro is currently unknown [13]. The differences in in-vivo and in-vitro solution chemistry from $\mathrm{pH}$ and chemically reactive species generated from the immunological responses have been mentioned but there are other factors that could provide clues to the difference in dissolution rates. The linear rate of dissolution is interesting particularly when compared to the typical immunological response in-vivo which shows various cell responses to the implant that increase and then decrease over time [30]. The measured in-vivo linear dissolution rate may indicate that what is responsible for the rapid dissolution rate in-vivo may not be a result of the immunological response (decreased $\mathrm{pH}$, peroxide, hypochlorite, free radicals, etc.) but rather some other constituent in the body that is more constant over time. This may or may not be the case since the foreign body reaction, consisting primarily of macrophages or foreign body giant cells, may persist at the tissue/implant interface for the lifetime of the implant [30], [31].

Exponent has demonstrated that significant increases in silica dissolution can be achieved in simulated in-vitro environments through the use of Fenton's reaction to generate free radicals in the presence of peroxide in PBS type solutions; however these rates are still about a factor of 4 to 6 lower than what is observed in-vivo.

Such differences between in-vitro and in-vivo testing are troubling since there are chemical or electrochemical processes that are occurring in-vivo that are not being duplicated in-vitro.

\section{Conclusions}

1. Ion dissolution in-vivo can affect biocompatibility and the corrosion of medical devices.

2. There are no known comparisons of in-vivo and in-vitro metal leaching rates.

3. There are examples of in-vivo dissolution (silica dissolution) that cannot currently be duplicated in-vitro.

4. Such discrepancies between in-vitro and in-vivo dissolution or leaching of ions make it difficult to evaluate the long-term reliability of implantable medical devices from in-vitro testing. 


\section{References}

[1] Ratner, B.D., Correlation of Material Surface Properties with Biological Responsed, in Biomaterials Science: An Introduction to Materials in Medicine, B.D. Ratner, et al., Editors. 1996, Academic Press: San Diego, CA.

[2] ASTM F 746-87, Standard Test Method for Pitting or Crevice Corrosion of Metallic Surgical Implant Materials, in Annual Book of ASTM Standards. 1987, American Society for Testing and Materials: Philadelphia. p. 221-226.

[3] ASTM F 2129-08, Standard Test Method for Conducting Cyclic Potentiodynamic Polarization Measurements to Determine the Corrosion Susceptibility of Small Implant Devices, in Annual Book of ASTM Standards. 2008, American Society for Testing and Materials: Philadelphia, PA. p. 1684-1690.

[4] Eiselstein, L.E., et al., Acceptance criterion for the corrosion resistance of medical devices: A statistical study of the pitting susceptibility of Nitinol, accounting for the in-vivo environment, in SMST 2008 - International Conference on Shape Memory and Superelastic Technologies. 2008, ASM: Stresa, Italy.

[5] Eiselstein, L.E., D.M. Proctor, and T.C. Flowers, Trivalent and Hexavalent Chromium Issues in Medical Implants. Materials Science Forum, 2007. Vols. 539543: p. pp. 698-703.

[6] Herting, G., I. Odnevall Wallinder, and C. Leygraf, Metal release from various grades of stainless steel exposed to synthetic body fluids. Corrosion Science, 2007. 49(1): p. 103-111.

[7] Herting, G., I. Odnevall Wallinder, and C. Leygraf, Factors that influence the release of metals from stainless steels exposed to physiological media. Corrosion Science, 2006. 48(8): p. 2120-2132.

[8] Ornberg, A., et al., Corrosion Resistance, Chemical Passivation, and Metal Release of $35 \mathrm{~N}$ LT and MP35N for Biomedical Material Application. Journal of The Electrochemical Society, 2007. 154: p. C546.

[9] Clausen, J., Commentary: Man, machine and in between. Nature, 2009. 457(7733): p. 1080-1081.

[10] Guyer, E., L. Eiselstein, and P. Verghese, Accelerated Testing of Active Implantable Medical Devices, in NACE2009. 2009, National Association of Corrosion Engineers: Atlanta, GA.

[11] Hämmerle, H., et al., Biostability of micro-photodiode arrays for subretinal implantation. Biomaterials, 2002. 23(3): p. 797-804.

[12] Maloney, J.M., et al. In-vivo Biostability of CVD Silicon Oxide and Silicon Nitride Films. 2005: Warrendale, Pa.; Materials Research Society.

[13] Rojahn, M., Encapsulation of a retina implant, in Electrical Engineering and Information Technology. 2003, University of Stuttgart: Stuttgart, Germany.

[14] Mazer, J.J. and J.V. Walther, Dissolution kinetics of silica glass as a function of $\mathrm{pH}$ between 40 and 85 C. Journal of non-crystalline solids, 1994. 170(1): p. 32-45.

[15] Brady, P.V. and J.V. Walther, Kinetics of quartz dissolution at low temperatures. Chemical geology, 1990. 82(3-4): p. 253-264.

[16] Icenhower, J.P. and P.M. Dove, The dissolution kinetics of amorphous silica into sodium chloride solutions: effects of temperature and ionic strength. Geochimica et Cosmochimica Acta, 2000. 64(24): p. 4193-4203. 
[17] Grambow, B., Corrosion of Glass, in Uhlig's Corrosion Handbook, R.W. Revie, Editor. 2000, John Wiley \& Sons, Inc.: New York, New York.

[18] Christensen, V.R., et al., Effect of chemical composition of man-made vitreous fibers on the rate of dissolution in vitro at different pHs. Environmental Health Perspectives, 1994. 102(Suppl 5): p. 83.

[19] ATSDR, Toxicological Profile for Synthetic vitreous fibers, September. 2004, U.S. Department of Health and Human Services, Public Health Service, Agency for Toxic Substances and Disease Registry: Atlanta, Georgia.

[20] Guldberg, M., et al., Measurement of In-vitro Fibre Dissolution Rate at Acidic pH. Annals of Occupational Hygiene, 1998. 42(4): p. 233-243.

[21] Baillif, P., et al., Dissolution kinetics of glass fibres in saline solution: in vitro persistence of a sparingly soluble aluminum-rich leached layer. Journal of Materials Science, 1995. 30(22): p. 5691-5699.

[22] Baillif, P., B. Chouikhi, and J.C. Touray, Dissolution mechanisms of boro-silicate glass fibres in saline solution with added dissolved silica. Journal of Materials Science, 2000. 35(4): p. 967-973.

[23] Karlsson, M., et al., Surface charge concentrations on silica in different 1.0 m metalchloride background electrolytes and implications for dissolution rates. Aquatic Geochemistry, 2001. 7(1): p. 13-32.

[24] Dove, P.M., The dissolution kinetics of quartz in aqueous mixed cation solutions. Geochimica et Cosmochimica Acta, 1999. 63(22): p. 3715-3728.

[25] Bennett, P.C., Quartz dissolution in organic-rich aqueous systems. Geochim. Cosmochim. Acta, 1991. 55: p. 1781-1797.

[26] Brady, P.V. and J.V. Walther, Controls on silicate dissolution rates in neutral and basic $\mathrm{pH}$ solutions at $25 \mathrm{C}$. Geochimica et Cosmochimica acta, 1989. 53(11): p. 2823-2830.

[27] Jendoubi, F., A. Mgaidi, and M. El Maaoui, The Dissolution Kinetics of Sand as Function of Particle Size. Canadian Journal of Chemical Engineering, 1998. 76: p. 233-238.

[28] Hench, L.L. Corrosion of Silicate Glasses: An Overview. in Materials Stability and Environmental Degradation, Symposium held April 5-7, 1988. 1988. Reno, Nevada, U.S.A.: MRS Pittsburgh, Pennsylvania.

[29] Cailleteau, C., et al., Insight into silicate-glass corrosion mechanisms. Nature Materials, 2008. 7(12): p. 978-983.

[30] Anderson, J.M., et al., Host Reactions to Biomaterials and Their Evaluation, in Biomaterials Science: An Introduction to Materials in Medicine, B.D. Ratner, et al., Editors. 1996, Academic Press: San Diego, CA.

[31] Coury, A.J., et al., Degradation of Materials in the Biological Environment, in Biomaterials Science: An Introduction to Materials in Medicine, B.D. Ratner, et al., Editors. 1996, Academic Press: San Diego, CA. 